\title{
First Case Report of Kidney Transplantation in Identical Twins: A Single Centre Experience
}

\author{
Eriawan Agung Nugroho ${ }^{1}$, Dila Junita ${ }^{2 *}$, IvaniYunita Korwa ${ }^{2}$ \\ ${ }^{1}$ Department of Urology, Faculty of Medicine Diponegoro University, Dr. Kariadi General Hospital, Semarang, \\ Jawa Tengah, Indonesia \\ ${ }^{2}$ Department of General Surgery, Faculty of Medicine Diponegoro University, Dr. Kariadi General Hospital, \\ Semarang, Jawa Tengah, Indonesia
}

*Corresponding Author: Dila Junita, Department of General Surgery, Faculty of Medicine Diponegoro University, Dr. Kariadi General Hospital, Semarang, Jawa Tengah, Indonesia, E-mail: junitadila@gmail .com

\begin{abstract}
Introduction: The number of kidney transplant among twin patient in worldwide is still low. Data showed that there were 120 living identical thin donor renal transplants in United States and 12 in the United Kingdom for period 16 year. Here we present the first case of kidney transplantation of identical twins in our center, including the operation technique, therapeutic regimens and patient outcome during hospitalization follow-up.
\end{abstract}

Case Presentation: A 42-year-old Melanesia male with a history of End Stage of Renal Disease received a living related renal transplant from his HLA identical twin brother. The left kidney of donor transplanted on the right side of recipient. The recipient received steroid and immunosuppression maintenance. He experienced immediate graft function with no evidence of acute allograft rejection or infectious complication.

Discussions: Many studies have shown that renal transplant among monozygotic twins has a low risk of allograft rejection but it remains controversial regarding the immunosuppressive therapy. The aim of steroid therapy is to preventing ischaemia-reperfusion damage, and the use of immunosuppressive therapy to reduce the risk of acute rejection. It is important to evaluated serum creatinine and urine output measurement to monitor graft function immediately after transplantation to provide an insight into the long-term function of the graft.

Conclusion: This is the first case report of kidney transplantation in identical twins in our health center, shown a good outcome of graft function and no infectious complications after transplant

Keywords: kidney transplantation, twin, identical twin, case report

Abbreviations: AHG: Anti-human Globulin, CIT: Cold Ischemic Time, ESRD: End Stage of Renal Disease, HLA: Human Leukocyte Antigen, POD: Post-operative Day, UNOS: United Network for Organ Sharing, UKT: UK Transplan, WIT: Warm Ischemic Time,

\section{INTRODUCTION}

It's been more than sixty years since the first successful renal transplant between the two identical twins. [1, 2]This was performed by Joseph Murray on December 23, 1954 at the Peter Bent Brigham Hospital in Boston, USA.

The graft functioned immediately and survived for 9 years without immunosuppression, before dying of a myocardial infarction. [3, 4]

Following this first kidney transplantation, a large number of successful renal transplantations between identical twins were reports in the 1950s and 1960s [5, 6].
But, there are no sources that provide valid data for kidney transplantation in identical twins in worldwide, especially in Indonesia.

The rate for kidney transplantation among identical twins is still low, as shown by United Network for Organ Sharing (UNOS) and UK Transplant (UKT) that there were 120 living identical thin donor renal transplants in United States and 12 in the United Kingdom for 16 year, during 1988-2004.[7]

The outcomes for homozygous twins are very various. Due to extremely similar between 
homozygous twins genetic, immunosuppressive regimens can theo-reticccally be avoided.

However, any individual who receives a new kidney has a high risk of the initial kidney disease returning just as much as new-onset nephropathy. Furthermore, immunosuppressive regimens can treat both pathological conditions $[8,9]$.In fact, two of the first twins transplanted by Murray develop glomerulonephritis and eventually died because of this.

At the beginning, it was thought that bilateral native nephrectomy would reduce the risk of recurrence but with time shown that this was not the case. Later on, azathioprine and steroids were introduced to overcome the problem of recurrence but not all transplant units found this necessary $[8,9]$.

From this case, the use of immunosuppressive regimens when the donor and the recipient of the kidney transplant are identical twins must be considered. [10] Here we present the first case of kidney transplantation of identical twins in our center, including the operation technique, therapeutic regimens and patient outcome during hospitalization follow-up.

\section{CASe Presentation}

A 42-year-old Melanesia male with a history of ESRD (End Stage of Renal Disease) secondary to hypertension received a living related renal transplant from his HLA identical twin brother. Prior to transplantation, he had been on hemodialysis for 13 months.

Monozygosity was not analyzed by DNA techniques, zygosity was being assumed from HLA typing. Additionally, he was found to be 16 matches on HLA typing and had a negative anti-human globulin (AHG) crossmatch.

The healthy potential donor (identical twin brother) has evidence of normal renal function bilaterally, free from infection, have a normal lower urinary tract and has sufficient understanding of the significance of a unilateral nephrectomy.

\subsection{Operative Technique}

The operation consists of two simultaneous operations in two adjacent operating rooms, the nephrectomy and the transplantation.

The nephrectomy of left kidney on a healthy donor requires careful dissection of the vasculature to obtain maximum length of the renal artery and vein (Figure 1.).

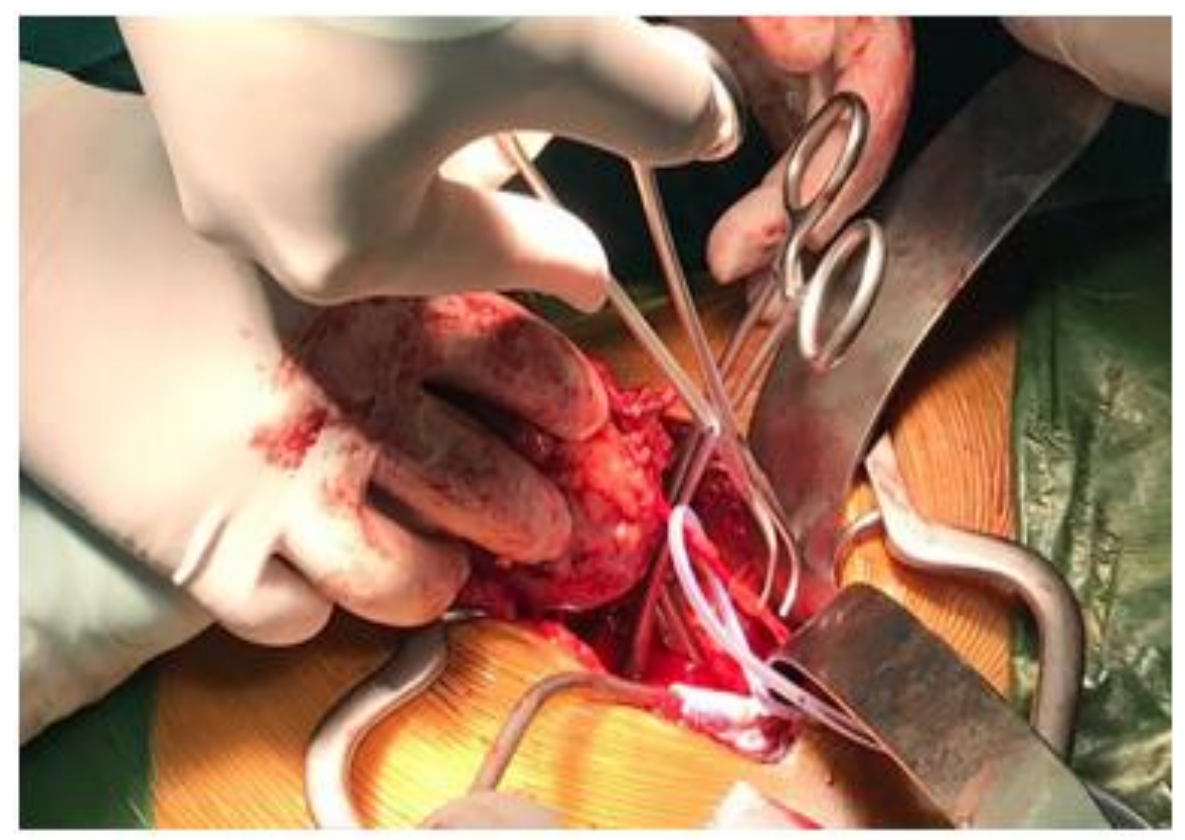

Figure1. Clamping of renal blood supply from the donor

After the kidney taken from the donor, the kidney was diluted with normal saline solution in a cold storage (Fig2.).

The recipient site is prepared in the right lower quadrant retroperitoneally exposing the iliac vessels from the bifurcation of the aorta to the inguinal ligament. The retroperitoneal area is dissected widely in a lateral direction to allow room for the kidney.

The renal artery is anatomosed end-to-side to the external iliac artery and the renal vein endto-side to the external iliac vein (Figure 3.). The ureter is passed through a muscular tunnel and sutured to the bladder mucosa. 


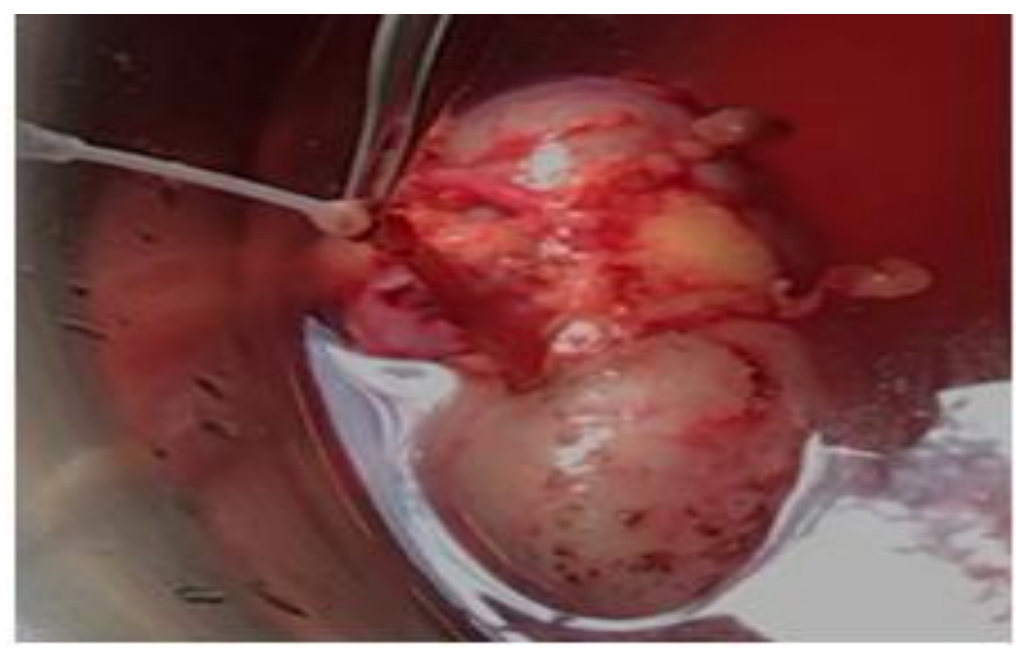

Figure2. The donor's kidney in a cold storage

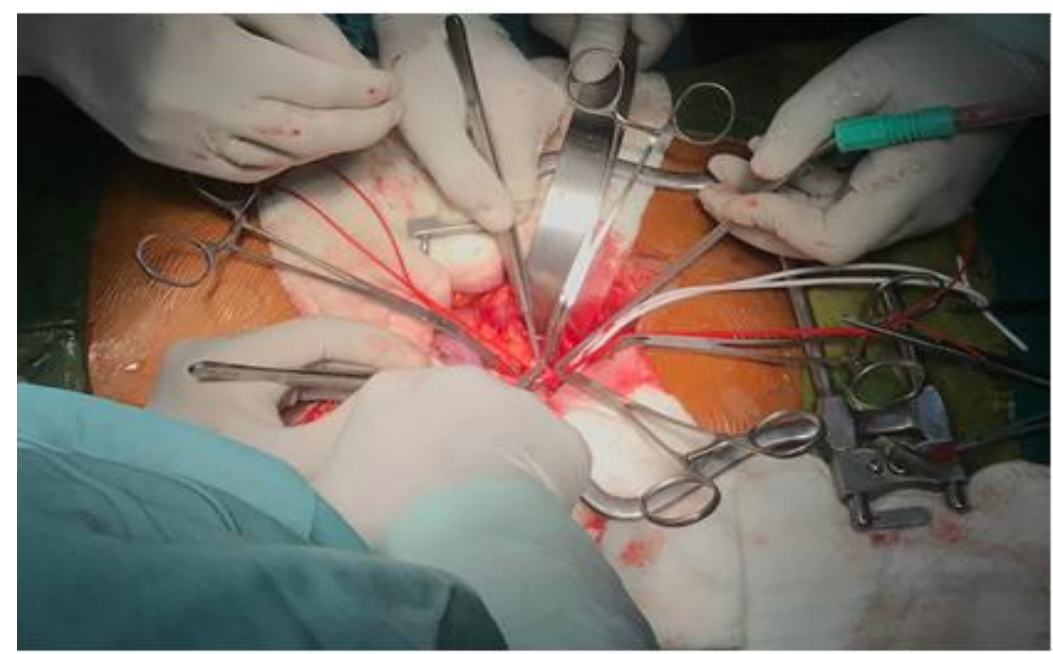

Figure3. Vascular anastomosis of renal transplant in recipient

\subsection{Warm and Cold Ischemia Time}

The time lapse from clamping of blood supply in the donor to its restoration in the recipient has been $44 \mathrm{~min} 23 \mathrm{~s}$ that known as total ischemic time.

The total ischemic time divided into warm and cold ischemic times, with the warm ischemic time (WIT) I and II were $13 \mathrm{~m} 28 \mathrm{~s}$ and $22 \mathrm{~m} 16 \mathrm{~s}$, respectively. The cold ischemia time (CIT) was 8 min39s. Urine flow starts immediately after 9 seconds after transplantation.

\subsection{Therapeutic Regimen}

The donor received a 3-day course of steroids, consisting of methyl-prednisolone $500 \mathrm{mg}$ intraoperatively, followed by $250 \mathrm{mg}$ and 125 mg on postoperative days (POD) $1 \& 2$, respectively. $\mathrm{He}$ also received maintenance immunosuppression of tacrolimus $0.2 \mathrm{mg} / \mathrm{kg}$ per day every 8 hours orally, basiliximab $20 \mathrm{mg}$ daily intravenously and mycophenolic acid $1 \mathrm{~g}$ every 12hours intravenously.

Opportunistic infection prophylaxis was also provided such as fungal prophylaxis with oral cotrimoxazole $10 \mathrm{mg}$ three times daily and valganciclovir $450 \quad-\quad m g$ daily for cytomegalovirus (CMV) prophylaxis.

\subsection{Post-Operative Course}

The donor is living and well without disability. The recipient developed functioning transplants with the biochemical changes of serum creatinine returning to normal (Fig4.), with average serum creatinine post-operative was $2,76 \mathrm{mg} / \mathrm{dL}$.

The diuresis reached $8.3 \mathrm{cc} / \mathrm{kg} \mathrm{BW} /$ hour (Body weight $80 \mathrm{~kg}$ ) for the first 24 hours, and gradually tapered off to normal ranges (Fig 5)

He experienced immediate graft function and was discharged with no complications on postoperative day (POD) 12\&serum creatinine was $1.1 \mathrm{mg} / \mathrm{dL}$.

The patient has no evidence of acute allograft rejection along the hospitalization, also no infectious complications from immunosuppression. No urinary retention, operative wound site infection or severe pain (Visual analogue scale $\geq 7$ ) were recorded. 
On abdominal ultrasound (Fig6.) post-operative day (POD) 1 showed that renal size was normal, no pelvicalyceal system dilatation, no perirenal fluid collection was observed.
In color doppler ultrasound showed that the blood flow distributed till the peripheral of the renalparenchym.

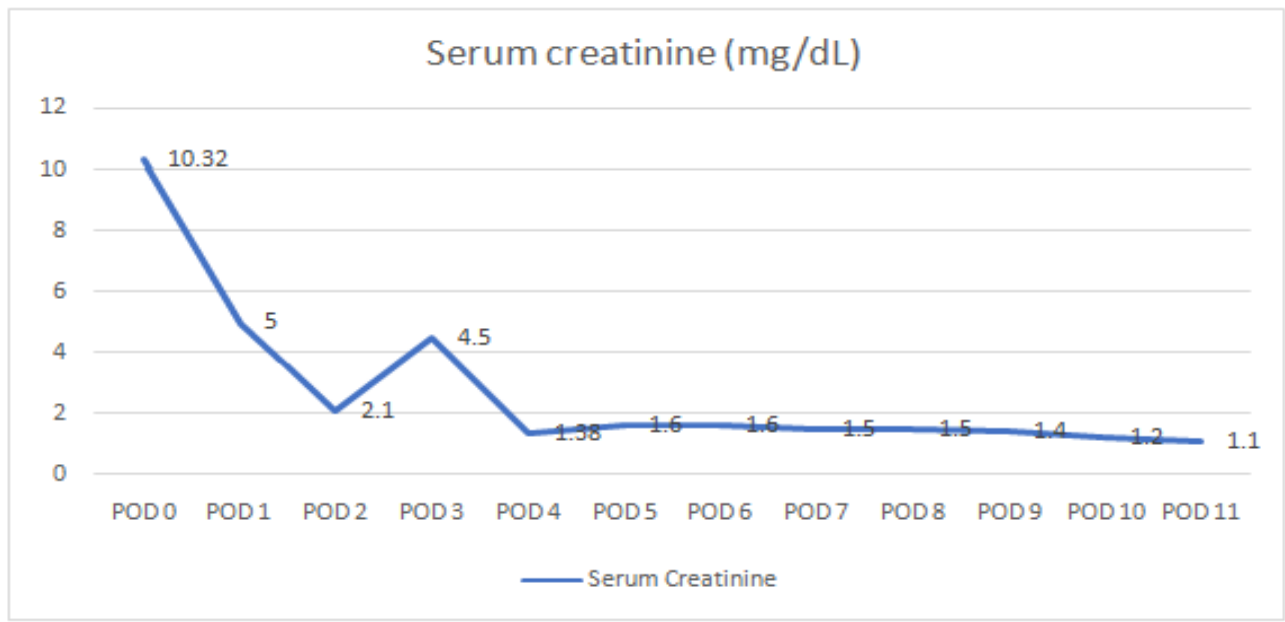

Figure4. Serum creatinine trend after transplantation

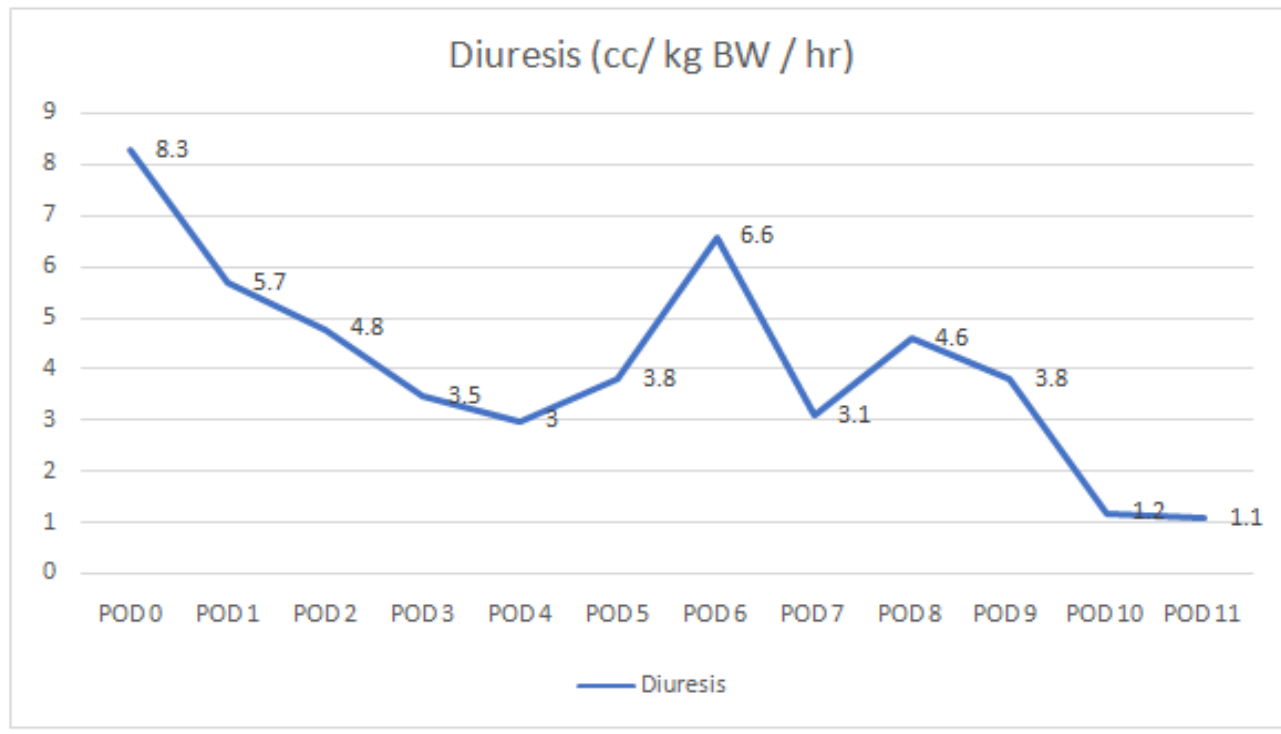

Figure5. Diuresis after transplantation

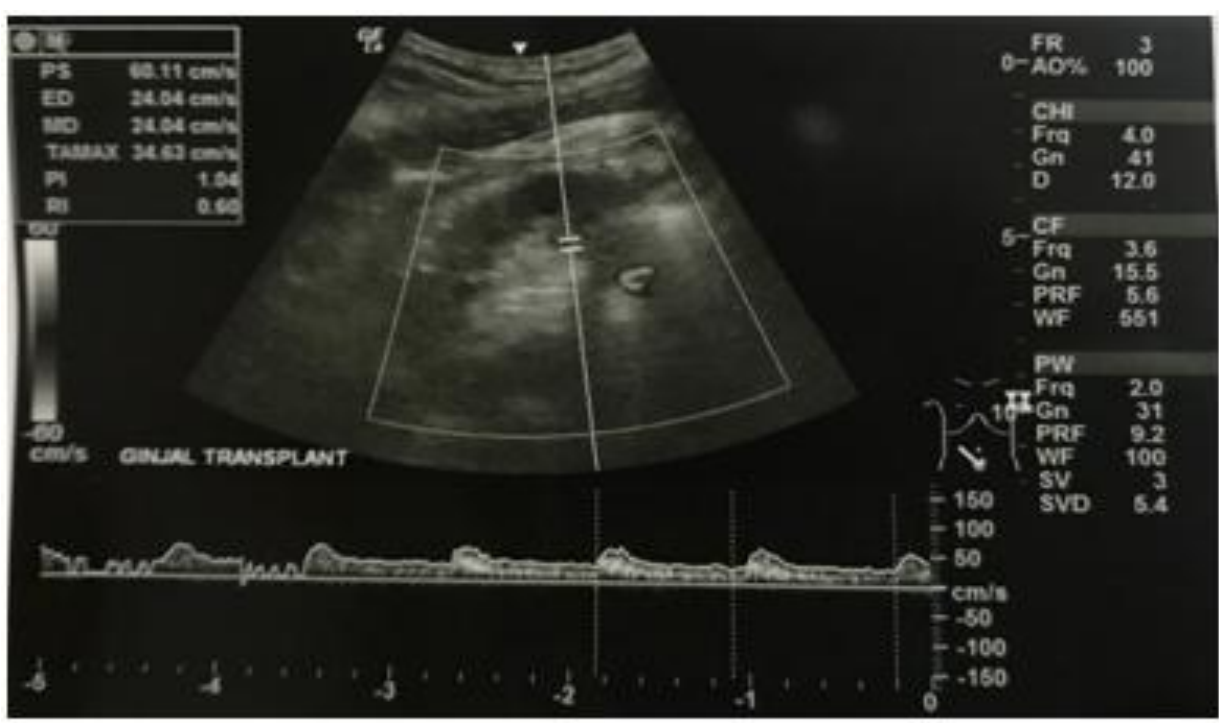

Figure6. Post-operative abdominal ultrasound 


\section{DISCUSSION}

Living donor transplantation offers better renal survival, better quality of life, and cost-effective treatment [12] many studies have shown that renal transplant among monozygotic twins is the best treatment option with excellent renal and overall survival.

Low risk of allograft rejection but there is disagreement regarding the immunosuppressive therapy they should receive. 13

Kessaris et al. showed that in the United Kingdon more than $50 \%$ and the in the USA more than two-third of patients with a renal transplant from their identical twin were receiving long-term immunosuppressive therapy 14

Where as in review by Krishnan et al. of the Organ Procurement Transplant Network database from 1987 to 2006, has shown that $71 \%$ of patients with a transplant from an identical twin stopped immunosuppressive therapy at 1 year, 33\% continued with some type of immunosuppression, and $13 \%$ continued with standard triple therapy.

In the survival analysis the group that stopped immunosuppression had better renal survival at 1 year. 13

This was the first kidney transplantation in twin that performed in our health center. A 42-yearoldmale with a history of ESRD (End Stage of Renal Disease) secondary to hypertension received a living related renal transplant from his HLA identical twin brother.

The patient received methylprednisolone 500 $\mathrm{mg}$ intraoperatively, followed by $250 \mathrm{mg}$ and $125 \mathrm{mg}$ on postoperative days (POD) 1 and 2, respectively. The aim of steroid therapy is to preventing ischaemia-reperfusion damage.

Damage from ischaemia reperfusion during surgery activates cytokines that can activate the immune response despite complete HLA identity between the donor and recipient.

It has also been described that ischaemia can modify donor DNA and genetic expression posttransplant.[15]Therefore; we suggest the use of immunosuppressive therapy to block the immune response at several levels and reduce the risk of acute rejection. The patient has no evidence of acute allograft rejection along the hospitalization, also no infectious complications from short-term immunosuppression.

There were not much different in operation technique of kidney transplant in this patient compared to common kidney transplantation.
The donor has underwent several screenings to prove the evidence of normal renal function, infection free, normal lower urinary tract and has sufficient understanding of the significance of a unilateral nephrectomy.

In procedural time, the recipient warm ischemic time II was $22 \min 16$ s which shorter than mean of warm ischemic time II (27.9min) in kidney transplants in national level.

The length of stay of this recipient (12 days) was in the range of average length of stay in overall kidney transplant in Indonesia. 15

Renal allograft dysfunction is common complication post transplantation and can lead to a graft dysfunction.

Creatinine, a product of muscle breakdown, is widely used as a marker of renal function as it is excreted in the glomerulus and to a lesser extent the proximal tubule. In this study showed that the average serum creatinine post-operative in recipient was $2,76 \mathrm{mg} / \mathrm{dL}$. Range from 10.32 $\mathrm{mg} / \mathrm{dL}$ (POD 0) gradually decline to $1.1 \mathrm{mg} / \mathrm{dL}$ in 12 days (Figure 4.).

Hariharan et al. reported that the improved halflife in recent years was seen predominantly in those patients with one-year creatinine value $<1.5 \mathrm{mg} / \mathrm{dL}$.

In the setting acute rejection, the preservation of renal function that is more important for graft survival. $[11,13]$

This study also provides urine output measurement as early clinical parameters, that collected on a routine basis to monitor graft function immediately after transplantation to provide an insight into the long-term function of the graft. Other studies have indicated that the magnitude of urine output is one of the most clinically used predictors for graft function immediately after reperfusion. 14

We evaluated the urine output from the POD 0 till patient discharged (Fig5). The diuresis reached 8.3 $\mathrm{cc} / \mathrm{kg} \mathrm{BW} / \mathrm{hour}$ for the first 24 hours, and gradually tapered off to normal ranges.

It is important to monitor the urine output after the transplant to evaluate the graft function.

As over infusion can lead to tissue edema with decreased tissue oxygenation and subjects vulnerable to suffer pulmonary edema, infections, myocardial ischemia, ileus, compromised renal flow, renal injury and even increased mortality [12]. 
Permanent function of a transplanted vascularized organ is possible between monozygotic (identical) twins by virtue of a genetic constitution which is identical gene for gene.

By contrast, transplantation between all other human being has failed after a variable period pf function, presumably because of an antibody response of the recipient developing against the nuclear antigen of the donor.11,14

\section{Conclusion}

This is the first case report of kidney transplantation in identical twins in our health center. As considering of acute graft rejection possibility, patient received immunosuppressant regiment, which has shown a good outcome of graft function and no infectious complications after transplant.

\section{REFERENCES}

[1] Merrill JP, Murray JE, Harrison JH, et al. Successful homotransplantation of the human kidney between identical twins. JAMA 1956; 160: 277.

[2] Merrill JP, Murray JE, Harrison JH, et al. Milestones in nephrology. renal homotranspl antation in identical twins. $J$ Am Soc Nephrol 2001; 12: 201

[3] Tilney NL. Renal transplantation between iden tical twins:A review. World J Surg 1986;10:381.

[4] Sayegh MH, Carpenter CB. Transplantation 50 years later-progress, challenges, and promises. N Engl J Med 2004; 351: 2761.

[5] Murray JE, Merrill JP, Harrison JH. Kidney transplantation between seven pairs of identical twins, Ann. Surg. 148 (1958) 343.

[6] Dossetor JB, Mackinnon KJ, Luke JC, et al. Renal transplantation between identical twins, Lancet 2 (1960) 572.
[7] Kessaris N, Mukherjee D, Chandak P, Mamode $\mathrm{N}$. Renal transplantation in identical twins in United Stated and United Kingdom. Transplntation. 2008; 86:1572-1577.

[8] Simmons RL, VanHook EJ, Yunis EJ, et al. 100 sibling kidney transplants followed 2 to 7 1/2 years: a multifactorial analysis, Ann. Surg. 185 (1977) 196-204.

[9] Shimmura H, Tanabe K, Ishida H, et al., Longterm results of living kidney transplantation from HLA-identical sibling donors under calcin eurin inhibitor immunosuppression, Int. J. Urol. 13 (2006) 502-508.

[10] Matas AJ,Payne WD, Sutherland DE, et al. 2,500 living donor kidney transplants: a singlecenter experience, Ann. Surg. 234 (2001) 149164.

[11] Dziewanowski K, Drozd R, Chojnowska A, Dziewanowska-Rogalska M, Parczewski M. Kidney transplantation among identical twins: therapeutic dilemmas. BMJ Case Reports 2011; doi:10.1136/bcr.01.2011.3752

[12] Haller M, Gutjahr G, Kramar R, Harnoncourt F, Oberbauer R. Cost-effectiveness analysis of renal replacement therapy in Austria. Nephrol Dial Transplant. 2011;26:2988-95.

[13] Krishnan N, Buchanan PM, Dzebisashvili N, Xiao H, Schinitzler MA, Brennan DC. Mono zygotic transplantation: concerns and opportun ities.Am J Transplant.2008;8:2343-51.

[14] Supit T, Nugroho EA, Santosa A, Soedarso MA, Daniswara N. Kidney transplantation in Indonesia : An update. Asian Journal of Urology (2019) 6, 305-411.

[15] Hariharan S, Mcbride MA, Cherikh WS, Tolleris CB, Bresnahan BA, et al. Posttranspla nt renal function in the first year predicts longterm kidney transplant survival. Kidney Intern ational (2002) 62, 311-318

Citation: Dila Junita, et.al. First Case Report of Kidney Transplantation in Identical Twins: A Single Centre Experience. ARC Journal of Urology.2019; 4(2): 6-11.doi:dx.doi.org/10.20431/2456-060X.0402002.

Copyright: (c) 2019 Authors. This is an open-access article distributed under the terms of the Creative Commons Attribution License, which permits unrestricted use, distribution, and reproduction in any medium, provided the original author and source are credited. 